DOI: $10.12731 / 2306-1561-2013-4-39$

\title{
PARAMETER OPTIMIZATION VEHICLE MAINTENANCE CONSUMERS CONCRETE MIXTURES
}

Bashmakov I.A., Polgun M.B., Ostroukh A.V.

\section{Abstract}

The paper proposes a methodology for the selection of rational parameters of the motor processes of customer service in terms of concrete mixtures multicriteriality, uncertainties and production risks. The problem bind consumers to a particular solution of the concretenode in the presence of deterministic and stochastic flows and applications, taking into account production risks.

Keywords: operational risks, transport, road transport, the concrete mix, concrete, technology, customer service, solution and concrete node, database, knowledge base.

УДК 656.025

\section{ОПТИМИЗАЦИЯ ПАРАМЕТРОВ ПРОЦЕССОВ АВТОТРАНСПОРТНОГО ОБСЛУЖИВАНИЯ ПОТРЕБИТЕЛЕЙ БЕТОННЫХ СМЕСЕЙ}

\section{Башмаков И.А., Польгун М.Б., Остроух А.В.}

\section{Аннотация}

В статье предложена методика выбора раџиональных параметров процессов автотранспортного обслуживания потребителей бетонных смесей в условиях многокритериальности, неопределенности и производственных рисков. Решена задача привязки потребителей к конкретному раствор-бетонному узлу (РБУ) при наличии детерминированных и случайных потоков заявок и учетом производственных рисков.

Ключевые слова: производственные риски, транспортировка, автомобильный транспорт, бетонная смесь, товарный бетон, технология, обслужсивание потребителей, раствор-бетонный узел, база данных, база знаний.

\section{Введение}

В настоящее время, несмотря на повсеместное применение технологии монолитного строительства, существует крайне мало методических разработок, направленных на совершенствование транспортного процесса доставки бетонных смесей $[1$ - 20]. В свою очередь, это обусловлено необходимостью одновременного учета ряда показателей при транспортировке бетонных смесей: 1) оно должно быть осуществлено точно в срок, 2) с изначально верно заданным и неизменным в процессе 
транспортировки смеси качеством, 3) а также правильным использованием бетонной смеси, ввиду того, что она после укладки безвозвратно теряет свои прежние свойства и приобретает иные.

Достаточно сложно разработать методику, способную учесть все приведенные показатели и улучшить работу технологии «производство-транспортировкапотребление» но это возможно, если рассматривать модели, методы и средства, автотранспортного обслуживания строительного производства как взаимосвязанный комплекс задач производства, транспортировки и использования бетонных смесей, материалов и строительных изделий на объектах строительства.

\section{Методика выбора рациональных параметров процессов автотранспортного} обслуживания потребителей бетонных смесей

Методика выбора рациональных параметров процессов автотранспортного обслуживания потребителей бетонных смесей приведена ниже и поясняется на примере с конкретными РБУ: ООО «СтройХолдинг»; ООО «База-Бетон»; ООО «ШмельБетон», на которых проводилось диссертационное исследование.

1) При детерминированных и случайных потоках заявок привязка пользователей к РБУ:

$$
\begin{aligned}
& \exists П П_{\text {РБУ }}, \Leftrightarrow\left(\mathrm{B}_{\mathrm{H}} \wedge \mathrm{K}_{\mathrm{H}} \wedge \mathrm{M}_{\mathrm{H}} \wedge \mathrm{B}_{\mathrm{H}_{1,2,3}}\right) \text {, } \\
& \text { с условием, что } \mathrm{b}_{\mathrm{H}_{1}}=\mathrm{CX}, \Leftrightarrow\left(\mathrm{B}_{\mathrm{H}} \wedge \mathrm{K}_{\mathrm{H}} \wedge \mathrm{M}_{\mathrm{H}}\right) \text {, } \\
& \neg \mathrm{S}_{\mathrm{H}_{1}} \Rightarrow \mathrm{b}_{\mathrm{H}_{2}}=\text { ББ, } \Leftrightarrow\left(\mathrm{B}_{\mathrm{H}} \wedge \mathrm{K}_{\mathrm{H}} \wedge \mathrm{M}_{\mathrm{H}}\right) \text {, } \\
& \neg \mathrm{S}_{\mathrm{H}_{2}} \Rightarrow \mathrm{S}_{\mathrm{H}_{3}}=\text { ШБ, } \Leftrightarrow\left(\mathrm{B}_{\mathrm{H}} \wedge \mathrm{K}_{\mathrm{H}} \wedge \mathrm{M}_{\mathrm{H}}\right) \text {, }
\end{aligned}
$$

где $\mathrm{B}_{\mathrm{H}}-$ необходимый срок; $\mathrm{K}_{\mathrm{H}}-$ необходимое количество бетонной смеси; $\mathrm{M}_{\mathrm{H}}-$ необходимая марка бетонной смеси; $5_{\mathrm{H}_{1,2,3}}$ - наибольшая близость РБУ к строящемуся объекту; СХ - РБУ ООО «СтройХолдинг»; ББ - РБУ ООО «База-Бетон»; ШБ - РБУ ООО «ШмельБетон».

2) Учет производственных рисков осуществляется с помощью ситуационной модели воздействия, которая представляет собой систему, реагирующую на выявленный риск рекомендациями по его минимизации.

Выявление риска здесь осуществляется за счет определения потенциальных и реализовавшихся угроз, а также установления возмущений, следующих за данными угрозами при практическом применении технологии. Сам процесс выявления риска становится доступным (возможным) благодаря структуризации рассматриваемой технологии, ввиду того, что при структурированной технологии четко прослеживаются все имеющиеся сбои и проблемы. Непосредственный порядок выявления рисков представлен на рисунке 1 . 
Шаг 1. Определение потенциальных и реализовавшихся угроз, их воздействие на технологию

Шаг 2. Определение возмущений, порожденных потенциальными и реализовавшимися угрозами в технологии

Шаг 3. Определение рисков, к которым приводят возмущения в рассматриваемой технологии

Рисунок 1. Порядок выявления рисков в технологии транспортирования бетонной смеси автомобильным транспортом

Порядок выявления рисков в рассматриваемой технологии на примере звена «погрузка бетонной смеси в транспортное средство» будет следующим:

Шаг 1. Определение угроз - загружаемая бетонная смесь часто бывает слишком жидкой/густой (некачественная работа бетоносмесительного завода).

Шаг 2. Определение возмущений - невозможность использования смеси в текущем виде.

Шаг 3. Определение рисков - дополнительные затраты времени и ресурсов на исправление ситуации.

С помощью вышеуказанного порядка выявления рисков в технологии транспортирования бетонных смесей можно выявить максимальное количество рисков, как потенциальных, так и уже реализовавшихся [1 - 3].

Затем, выявленные риски подвергаются анализу экспертным методом с использованием практического опыта экспертов, а также с учетом всех возможных источников тематической информации. В ходе данного анализа эксперты оценивают вероятность реализации конкретного риска, исходя при этом из следующих вариантов оценки: очень низкая, низкая, средняя, высокая.

Экспертным методом оценивают и степень тяжести возникших последствий от реализации выявленного риска исходя из следующих вариантов оценки: легкие, средние, тяжелые, очень тяжелые.

После экспертами строится диаграмма (рисунок 2) на которой обозначены границы допустимого риска, вероятность его реализации и тяжесть последствий.

Если точка, которой обозначено соотношение вероятности реализации риска с тяжестью его последствий лежит на границе, или выше нее - риск учитывают, в противном случае - нет. Учитываемые риски подлежат минимизации, о которой пойдет речь в следующем пункте. 


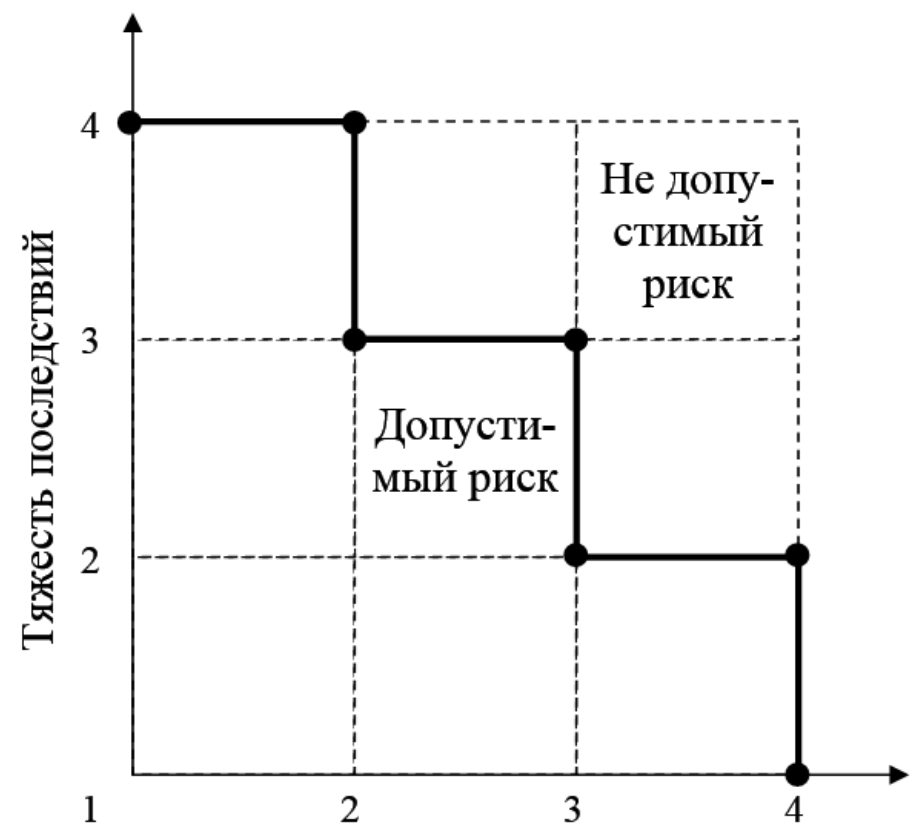

Вероятность реализации рисков

Рисунок 2 - Диаграмма анализа рисков

Допустимые затраты организации на минимизацию риска установлены на уровне окупаемости данных затрат. Если эффект от минимизации риска не окупает затрат на его минимизацию, то нет целесообразности в данных затратах.

Минимизация (предупреждение) некоторой части потенциальных рисков в технологии транспортирования бетонной смеси автомобильным транспортом может осуществиться за счет структуризации административных и производственных процессов данной технологии. А поскольку структурированная технология учитывает все особенности своих звеньев (этапов), то ее надежность имеет тенденцию повышаться.

Для минимизации уже выявленных и вновь возникающих рисков, что небыли минимизированы за счет структуризации рассматриваемой технологии, предлагается применять ситуационную модель воздействия, которая представляет собой систему, реагирующую на выявленный риск рекомендациями по его минимизации (как ответ, так и предупреждение). Она опирается на формирование в организации базы данных и базы знаний, связанных с технологией транспортирования бетонных смесей.

База данных - совокупность данных, касающихся технологии транспортирования бетонных смесей, хранимых в соответствии со схемой данных, манипулирование которыми выполняют с помощью правил моделирования данных $[18,19]$. Другими словами, базу данных можно пополнять новыми данными, которые представляют собой факт произошедшего события, но изменять (кроме удаления) эти данные нельзя. 
База знаний - это совокупность данных, касающихся технологии транспортирования бетонных смесей, которыми можно оперировать по усмотрению пользователя (добавлять, удалять, изменять) [16, 17]. Причем, информация в базе знаний может быть: констатирующая - утверждающая что-либо; интердикционная - запрещающая что-либо; побудительная - направляющая на действие в заданном направлении. В базе данных находится только констатирующая информация.

Принцип функционирования выше названной модели таков - все выявленные с помощью структурирования рассматриваемой технологии риски заносятся в базу данных. На каждый риск, экспертами, которые проводили анализ учета рисков, создается и вносится в базу знаний своё ситуационное (ответное или предупреждающее) воздействие, направленное на его минимизацию. Нахождение данных воздействий в базе знаний, позволяет изменять их при первой необходимости, делая актуальными, а также постоянно вносить новые. При проявлении риска из базы данных или при выявлении нового, в базе знаний осуществляется поиск воздействий на данный риск, с целью его минимизации.

\section{Оптимальная привязка потребителей к РБУ при наличии детерминированных и случайных потоков заявок и учетом производственных рисков}

Выявленные при структурировании технологии транспортирования бетонной смеси риски, представляются множеством «Р» и содержатся в базе данных: $\mathrm{P}=\left\{\mathrm{P}_{\mathrm{i}}\right\}$, $\mathrm{i}=(1, \mathrm{n})($ рисунок 3$)$.

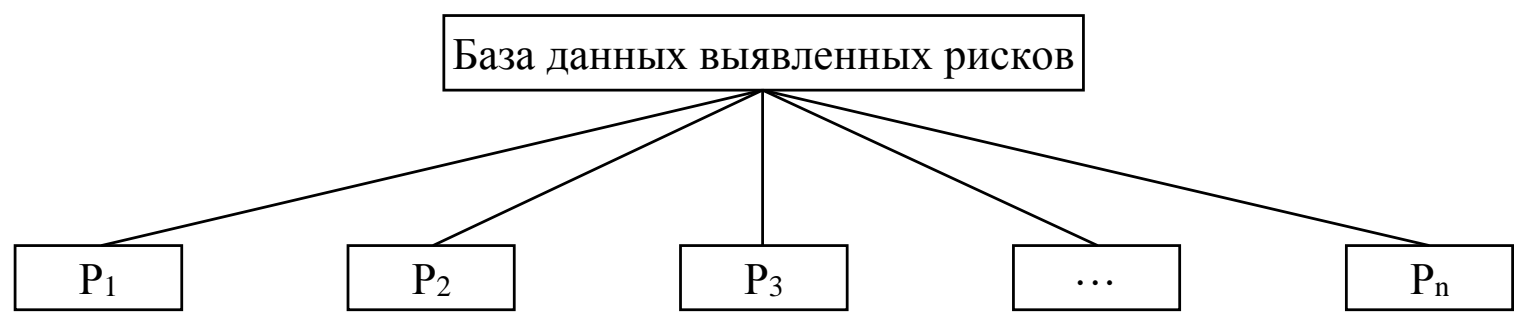

\section{Рисунок 3 - Выявленные риски}

В ней, согласно разработанной классификации и типизации рисков, возникающих при транспортировании бетонных смесей автомобильным транспортом, содержатся:

1. Риски организационного характера - типизируются на: а) недостатки (организационного процесса), б) нарушения (организационного процесса);

2. Риски технического характера - типизируются на: а) поломки, б) недостатки (необходимых качеств);

3. Риски эксплуатационного характера - типизируются на: а) несоблюдение (правил эксплуатации), б) недостатки (существующих принципов и правил эксплуатации); 
4. Риски производственного характера - типизируются на: а) несоответствие (заданным параметрам предмета или объекта труда), б) невозможность (накопить нужный предмет или объект труда).

На рисунке 3: $\mathrm{P}_{1}$ - затраты на использование наемного транспорта из-за технической неисправности собственных ТС организации; $\mathrm{P}_{2}$ - дополнительные затраты на исправление ситуации, а также снижение прочности готового изделия (вплоть до непринятия сдачи объекта в эксплуатацию) из-за слишком жидкой/густой загружаемой в автобетоносмеситель бетонной смеси; $\mathrm{P}_{3}$ - затраты на снижение качества готового изделия (вплоть до непринятия сдачи объекта в эксплуатацию), или же дополнительные затраты на очистку смесительного барабана, покупку новой порции смеси и ее транспортировку из-за лишнего времени, потерянного в дороге по причине: ДТП, дорожных заторов, технических неисправностей и др.; $\mathrm{P}_{\mathrm{n}}-\mathrm{n}$-й риск.

В соответствии с указанными рисками задаются множества ситуационных воздействий «В», которые позволяют минимизировать влияние риска и содержатся в базе знаний: $\mathrm{B}=\left\{\mathrm{B}_{\mathrm{i}}\right\}, \mathrm{i}=(1, \mathrm{n})$.

В качестве ситуационных (ответных и предупреждающих) воздействий используются организационно-технологические решения (рисунок 4).

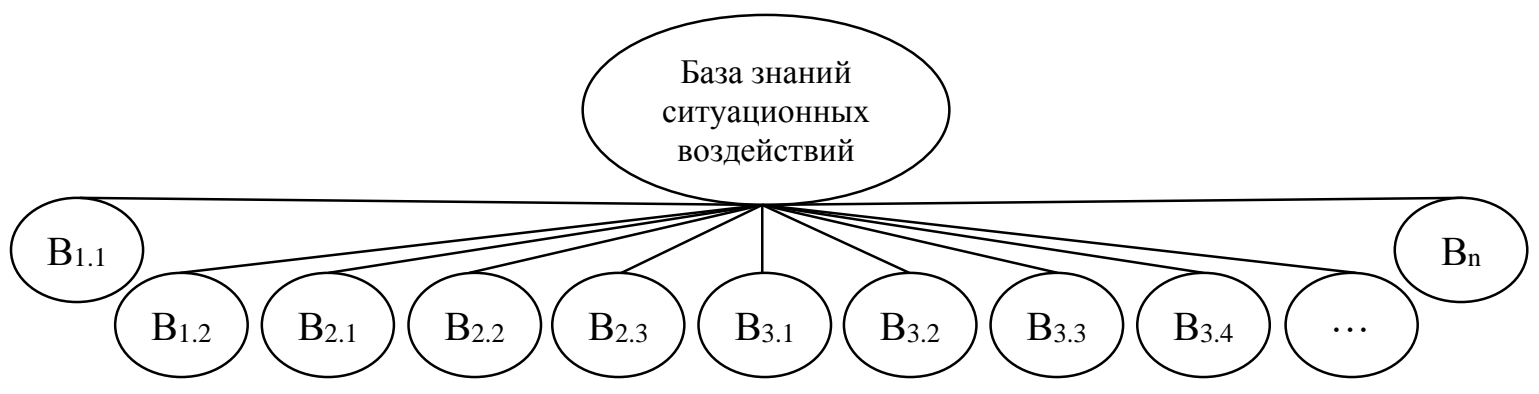

\section{Рисунок 4 - Организационно-технологические решения направленные на минимизацию выявленных рисков}

На рисунке 4: $\mathrm{B}_{1.1}$ - организовать подмену вышедшей из строя машины другой; $\mathrm{B}_{1.2}$ - организовать оперативный ремонт и устранить неисправность; $\mathrm{B}_{2.1}$ наблюдение водителем за состоянием смеси в процессе ее загрузки в ТС, и сообщение оператору бетоносмесительного завода об изменении консистенции смеси; $B_{2.2}$ - возвращение бетонной смеси на завод: слив раннее полученной смеси и замена ее новой (за счет производителя); В2.3 - в отдельных случаях возможно требование добавления специальных ингредиентов для приведения смеси в надлежащее состояние; В3.1 - направление на маршрут высокопрофессиональных водителей с обеспечением их технически исправными транспортными средствами; $\mathrm{B}_{3.2}$ - предрейсовое ознакомление водителей с альтернативными маршрутами следования от бетоносмесительного завода до строящегося объекта; В3.3 - для избегания дорожных заторов обеспечение водителей современными средствами

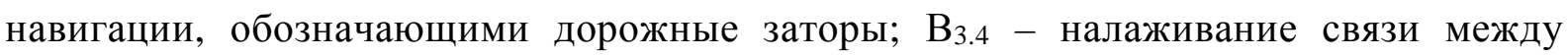


водителями автобетоносмесителей с целью передачи информации о текущих дорожных условиях на маршруте; $\mathrm{B}_{\mathrm{n}}$ - n-e ситуационное воздействие.

Необходимо отметить, что информация, содержащаяся в базах данных и базах знаний, должна отвечать следующим критериям надежности: быть обоснованной (валидной) - способной измерять что-либо (информация выступает в роли инструмента-измерителя); быть устойчивой - способной быть идентичной при получении в разных ситуациях; быть точной - являться чувствительным инструментом при своей валидности.

При условии определения множества выявленных рисков и ситуационных воздействий, осуществляется моделирование, которое выражается в виде выдачи рекомендаций (ответа или предупреждения) для минимизации выявленного риска $\left(\mathrm{P}_{1}\right.$, $\mathrm{P}_{2}, \ldots, \mathrm{P}_{\mathrm{n}}$ ) (таблице 1).

Итоговый результат рационализации:

$$
\begin{gathered}
\exists П \Pi_{\text {РБУдс }} \Leftrightarrow\left(\mathrm{B}_{\mathrm{H}} \wedge \mathrm{K}_{\mathrm{H}} \wedge \mathrm{M}_{\mathrm{H}} \wedge \mathrm{S}_{\mathrm{H}_{1,2,3}} \wedge \frac{\mathrm{P}_{\mathrm{n}}}{\mathrm{B}_{\mathrm{n}}}\right) \\
\text { с условием, что } \mathrm{Б}_{\mathrm{H}_{1}}=\mathrm{CX}, \Leftrightarrow\left(\mathrm{B}_{\mathrm{H}} \wedge \mathrm{K}_{\mathrm{H}} \wedge \mathrm{M}_{\mathrm{H}}\right), \\
\neg \mathrm{Б}_{\mathrm{H}_{1}} \Rightarrow \mathrm{S}_{\mathrm{H}_{2}}=\text { ББ, } \Leftrightarrow\left(\mathrm{B}_{\mathrm{H}} \wedge \mathrm{K}_{\mathrm{H}} \wedge \mathrm{M}_{\mathrm{H}}\right), \\
\neg \mathrm{Б}_{\mathrm{H}_{2}} \Rightarrow \mathrm{S}_{\mathrm{H}_{3}}=\text { ШБ, } \Leftrightarrow\left(\mathrm{B}_{\mathrm{H}} \wedge \mathrm{K}_{\mathrm{H}} \wedge \mathrm{M}_{\mathrm{H}}\right),
\end{gathered}
$$

\begin{tabular}{|c|c|}
\hline \multicolumn{2}{|r|}{ Название технологического звена } \\
\hline $\mathrm{P}_{1}$ & $\begin{array}{c}\frac{\mathrm{P}_{1}}{\mathrm{~B}_{1.1} \vee \mathrm{B}_{1.2} \vee \mathrm{B}_{1.3} \vee \mathrm{B}_{\mathrm{n}}} \\
\mathrm{B}_{1.1}-\text { первая предложенная мера минимизации выявленного риска; } \\
\mathrm{B}_{1.2} \text { - вторая предложенная мера минимизации выявленного риска; } \\
\mathrm{B}_{1.3} \text { - третья предложенная мера минимизации выявленного риска; } \\
\mathrm{B}_{\mathrm{n}}-\text { n-ная предложенная мера минимизации выявленного риска. } \\
\mathrm{P}_{1}-\text { первый выявленный риск. }\end{array}$ \\
\hline $\mathrm{P}_{2}$ & $\frac{\mathrm{P}_{2}}{\mathrm{~B}_{2.1} \vee \mathrm{B}_{2.2} \vee \mathrm{B}_{\mathrm{n}}}$ \\
\hline \multicolumn{2}{|r|}{ Название технологического звена } \\
\hline $\mathrm{P}_{3}$ & $\frac{\mathrm{P}_{3}}{\mathrm{~B}_{3.1} \vee \mathrm{B}_{3.2} \vee B_{n}}$ \\
\hline$P_{n}$ & $\frac{P_{n}}{B_{n}}$ \\
\hline
\end{tabular}

Таблица 1. - Процесс моделирования выдачи ситуационных (ответных или предупреждающих) воздействий 
Рационализация (через структуризацию) технологии транспортирования бетонных смесей автомобильным транспортом, используемая совместно с ситуационной моделью воздействия, позволяет минимизировать выявленные риски за счет выдачи организационно-технических решений внутри предприятия, для адекватной реакции на эти риски. Вследствие минимизации рисков надежность технологии повышается.

\section{Заключение}

Таким образом, разработана комплексная методика, позволяющая путем структуризации рационализовать технологию транспортировки бетонных смесей, затем проанализировать имеющиеся в ней риски, и минимизировать их, повышая надежность транспортных процессов технологии транспортировки бетонных смесей автомобильным транспортом.

Предложенная методика основана на использовании модели кортежей, разработанной во второй главе в результате чего, становится возможным выявление имеющихся в ней рисков (последние связаны с угрозами и возмущениями). Выбор рисков подлежащих минимизации проходит с применением экспертного метода, на основе ситуационной модели. Для подтверждения эффективности предложенной методики, в исследовании приведена формула определения надежности технологии.

Разработанная методика предложена впервые и ранее нигде не применялась. Для фактического доказательства состоятельности данной методики она была внедрена в организации ООО «ТехноМаш» и результаты этого внедрения представлены в четвертой главе настоящего исследования.

\section{Список информационных источников}

[1] Башмаков И.А., Покровский А.К. Математические модели в риск-менеджменте предприятий транспорта. Грузовое и пассажирское автохозяйство. 2010. № 7. С. 30-33.

[2] Башмаков И.А., Покровский А.К. О надежности и рисках в автотранспортных предприятиях. Грузовое и пассажирское автохозяйство. 2011. № 9. С. 66-69.

[3] Башмаков И.А., Покровский А.К., Комаров А.А. Риски производственных процессов. Транспорт: наука, техника, управление. 2012. № 1. С. 65-67.

[4] Будихин С.А. Сравнение методов вращения факторов для управления рисками на промышленных предприятиях / А.В. Остроух, А.В. Будихин, С.А. Будихин // Приборы и системы. Управление, контроль, диагностика. - М.: «Научтехлитиздат», 2008. - №10. - С. 60-63.

[5] Жарков Н.Н. Методы построения корпоративной информационной системы управления ресурсами строительного предприятия / Н.Н. Жарков, Т.В. Дорохина А.В. Остроух, Н.Е. Суркова // Вестник Российского нового университета. Серия естествознание, математика, информатика. - М.: РосНОУ, 2004. - Вып. 4. - С. 110113. 
[6] Кузнецов И.А. Особенности реализации автоматизированной информационноаналитической системы центра планирования перевозок строительных грузов / И.А. Кузнецов, А.В. Остроух // Вестник МАДИ(ГТУ). - 2008. - Вып. 1(12). - С. 92 96.

[7] Куфтинова Н.Г. Процессно-ориентированный подход к автоматизации планирования и управления транспортировкой продукции предприятий промышленности / А.В. Остроух, Н.Г. Куфтинова // Вестник МАДИ - 2010. - Вып. 4(23). - С. 62-66.

[8] Николаев А.Б. Информационные технологии в менеджменте и транспортной логистике: учебное пособие / А.Б. Николаев, А.В. Остроух. - Saint-Louis, MO, USA: Publishing House Science and Innovation Center, 2013. - 254 c. - ISBN 978-0615-67110-9.

[9] Остроух А.В. Основы построения систем искусственного интеллекта для промышленных и строительных предприятий: монография / А.В. Остроух. - М.: OОО «Техполиграфцентр», 2008. - 280 с. - ISBN 978-5-94385-033-2.

[10] Остроух А.В. Системы искусственного интеллекта в промышленности, робототехнике и транспортном комплексе: монография / А.В. Остроух Красноярск: Научно-инновационный центр, 2013. - 326 с. - ISBN 978-5-90631410-9.

[11] Остроух А.В. Автоматизация распределения транспортных средств и техники по объектам строительства с учетом организационных и технических факторов / А.В. Остроух, Н.Е.Суркова // Приборы и системы. Управление, контроль, диагностика. - М.: «Научтехлитиздат», 2004. - №12. - С. 6-9.

[12] Остроух А.В. Автоматизация и моделирование работы предприятий по строительству промышленных объектов: дис. ... д-ра техн. наук: 05.13.06: защищена 07.04.09: утв. 19.06.09. - М., 2009. - 357 с.

[13] Остроух А.В. Автоматизация и моделирование работы предприятий по строительству промышленных объектов: автореф. дис. ... д-ра техн. наук: 05.13.06. - М., 2009. - 43 c.

[14] Остроух, А.В. Информационные технологии в научной и производственной деятельности / [ред. А.В. Остроух] - М: ООО "Техполиграфцентр", 2011. - 240 с. ISBN 978-5-94385-056-1.

[15] Остроух А.В. Автоматизация управления строительным предприятием / А.В. Остроух // Приборы и системы. Управление, контроль, диагностика. - М.: «Научтехлитиздат», 2004. - №8. - С. 58-61.

[16] Остроух А.В., Башмаков И.А. Процессная модель технологии транспортировки бетонных смесей автомобильным транспортом // Автоматизация и управление в технических системах. - 2013. - № 4.1. - С. 75-81. DOI: 10.12731/2306-1561-20134-14.

[17] Остроух А.В., Джха Прабхакар Автоматизированная система управления складом железобетонных изделий // Автоматизация и управление в технических системах. - 2013. - № 4.1. - С. 51-56. DOI: 10.12731/2306-1561-2013-4-9.

[18] Порфирьева С.А. Автоматизированные информационные системы на автотранспортном предприятии / А.В. Остроух, К.А. Данчук, А.Б. Львова, С.А. 
Порфирьева, П.С. Якунин // В мире научных открытий. Серия «Проблемы науки и образования». - 2012. - №2.6 (26). - С.34-38.

[19] Суркова Н.Е. Методы проектирования информационных систем / А.В. Остроух, H.Е. Суркова - М.: РосHOУ, 2004. - 144 с. - ISBN 5-89789-021-8.

[20] Ostroukh A.V. Workflow automatization in preparation for building / A.V. Ostroukh, D.S. Tarasenko, D.I. Podporin, N.E. Surkova // Information and Telecommunication Technologies in Intelligent Systems: Proceeding of Fourth International Conference. May 27 - June 03, 2006, Catalina, Italy. pp. 102-104. 